\title{
PROGAME - AMBIENTE EDUCACIONAL GAMIFICADO COM ELEMENTOS DOS DESCRITORES DE MATEMÁTICA DO SISTEMA PERMANENTE DE AVALIAÇÃO DA EDUCAÇÃO BÁSICA DO CEARÁ
}

\author{
Francisco Aislan da Silva Freitas ${ }^{1}$, Paulo Henrique Mendes Maia ${ }^{1}$, Jezmael Oliveira Basílio ${ }^{2}$ \\ ${ }^{1}$ Universidade Estadual do Ceará (UECE) \\ Fortaleza - CE - Brasil \\ ${ }^{2}$ Universidade do Estado do Rio Grande do Norte(UERN) \\ Mossoró - RN - Brasil \\ \{aislansf, jezmaelbasilio\}@gmail.com, pauloh.maia@uece.br
}

\begin{abstract}
Gamification can be used as an interaction strategy that can stimulate the engagement of the public involved. This article presents the ProGame, a gamified environment that allows students to train through challenges for the mathematics tests of the Permanent System of Evaluation of Basic Education of Ceará (SPAECE). The usability of the environment was validated by 34 students of a class of the first year of high school in a state school in Ceará.
\end{abstract}

Resumo. Gamificação pode ser utilizada como uma estratégia de interação que pode estimular o engajamento do público envolvido. Este artigo apresenta o ProGame, um ambiente gamificado que permite estudantes treinarem por meio desafios para as provas de matemática do Sistema Permanente de Avaliação da Educação Básica do Ceará (SPAECE). A usabilidade do ambiente foi validada por 34 alunos de uma turma do $1^{\circ}$ ano do ensino médio de uma escola estadual do Ceará.

\section{Introdução}

Atualmente, as Tecnologias Digitais de Informação e Comunicação (TDIC) oferecem aos profissionais da educação estratégias essenciais para um melhor desempenho dos alunos no contexto escolar. Com o rápido avanço dessa área, é comum encontrar e utilizar diversos recursos educacionais, como softwares educativos e objetos de aprendizagem, para diferentes meios digitais, como compitadores, tablets e smartphones, proporcionando novas alternativas de ensino e aprendizagem.

Com isso, uma abordagem crescente é a utilização de jogos educativos [Moratori 2003] para ensino de diversas disciplinas. Dentro dos jogos pode-se trabalhar tanto as habilidades psicomotoras, como raciocínio lógico, quanto também as sociais, por meio de interação com outros jogadores. Estudos mostram que o uso de jogos educativos no ambiente escolar melhora a aprendizagem na medida em que complementam o processo de ensino tradicional [Alves 2015][Neto et al. 2015]. Além do uso de jogos educativos, o processo de gamificação, que aplica elementos e técnicas de design de games a vivências e contextos não caracterizados como games [Fardo 2014], vem sendo 
VII Congresso Brasileiro de Informática na Educação (CBIE 2018)

Anais dos Workshops do VII Congresso Brasileiro de Informática na Educação (WCBIE 2018)

cada vez mais utilizado com sucesso como ferramenta importante para a aprendizagem [Alves 2015][Simone de S. Borges 2013][Luma da Rocha Seixas 2014][Neto et al. 2015].

Este trabalho propõe um ambiente gamificado, chamado ProGame, para que alunos do 10 ano do ensino médio possam se preparar para o Sistema Permanente de Avaliação da Educação Básica do Ceará ${ }^{1}$ (SPAECE), que avalia as escolas públicas das redes estadual e municipais do estado do Ceará nas disciplinas de língua portuguesa e matemática. O SPAECE aplica provas para avaliar os conhecimentos dos alunos nesses assuntos, permitindo que as escolas possam visualizar, através de indicadores, a evolução dos seus alunos nessas matérias, e o estado pode acompanhar o desempenho das escolas e monitorar se os níveis de aprendizagem estão dentro dos parâmetros de qualidade educacional por ele definidos. O ambiente aqui proposto contempla apenas o conteúdo de matemática e permite os professores criarem desafios de diferentes níveis para os alunos treinarem e competirem entre si utilizando mecanismos como ranking, pontuação, e premiação, dentre outros.

O restante deste trabalho está dividido nos seguintes capítulos: no capítulo 2 discute os principais conceitos relacionados a gamificação, enquanto o capítulo 3 são descritas as principais funcionalidades do ProGame. No capítulo 4 são mostrados os resultados da avaliação de usabilidade dos alunos usuários do ambiente gamificado. Por fim, no capítulo 5 são expostas as considerações finais.

\section{Gamificação}

O termo "gamificação" (do original inglês: gamification) significa a aplicação de elementos utilizados no desenvolvimento de jogos eletrônicos, tais como estética, mecânica e dinâmica, em outros contextos não relacionados a jogos [Kapp 2012]. A gamificação é um fenômeno emergente, que deriva diretamente da popularização e popularidade dos games, e de suas capacidades intrínsecas de motivar a ação, resolver problemas e potencializar aprendizagens nas mais diversas áreas do conhecimento e da vida dos indivíduos. Esse potencial que os games apresentam já havia sido percebido há mais de três décadas [Cysneiros 2008]. Porém, naquele tempo, a indústria dos games ainda estava se consolidando. Atualmente, pode-se dizer que influência dessa forma de entretenimento é global e atinge praticamente todas as camadas da população.

Originada como método aplicado em programas de marketing e aplicações para web, com a finalidade de motivar, engajar e fidelizar clientes e usuários [Zichermann and Cunningham 2011], a gamificação pressupõe a utilização de elementos tradicionalmente encontrados nos games, como narrativa, sistema de feedback, sistema de recompensas, conflito, cooperação, competição, objetivos e regras claras, níveis, tentativa e erro, diversão, interação, interatividade, entre outros, em outras atividades que não são diretamente associadas aos games, com a finalidade de tentar obter o mesmo grau de envolvimento e motivação que normalmente encontramos nos jogadores quando em interação com bons games.

O objetivo é conseguir visualizar um determinado problema ou contexto e pensar soluções a partir do ponto de vista de um game designer (profissional responsável pela criação de jogos eletrônicos), já que esse profissional geralmente é capacitado a produzir experiências que concentram a energia e o foco de muitos indivíduos para resolver

\footnotetext{
${ }^{1}$ http://www.spaece.caedufjf.net/
} 
VII Congresso Brasileiro de Informática na Educação (CBIE 2018)

Anais dos Workshops do VII Congresso Brasileiro de Informática na Educação (WCBIE 2018)

problemas em mundos virtuais [McGonigal 2011]. Porém, a gamificação não implica em criar um game que aborde o problema, recriando a situação dentro de um mundo virtual, mas sim em usar as mesmas estratégias, métodos e pensamentos utilizados para resolver aqueles problemas nos mundos virtuais em situações do mundo real.

Para situá-la e diferenciá-la de outros contextos semelhantes, a Figura 1 posiciona a gamificação entre dois eixos. O horizontal traz a ideia de um jogo completo até as suas partes (elementos) e o vertical vai da brincadeira (livre e descontraída) para o jogo (mais formal). Sendo assim, a gamificação pressupõe o uso de elementos dos games, sem que o resultado final seja um game completo, e também se diferencia do design lúdico na medida em que este pressupõe apenas um aspecto de maior liberdade, de forma lúdica, quanto ao contexto em que está inserido. Em outras palavras, nessa concepção, abordar um problema de forma lúdica não implica em contemplar objetivos e seguir uma metodologia mais precisa, que é o que a gamificação propõe.

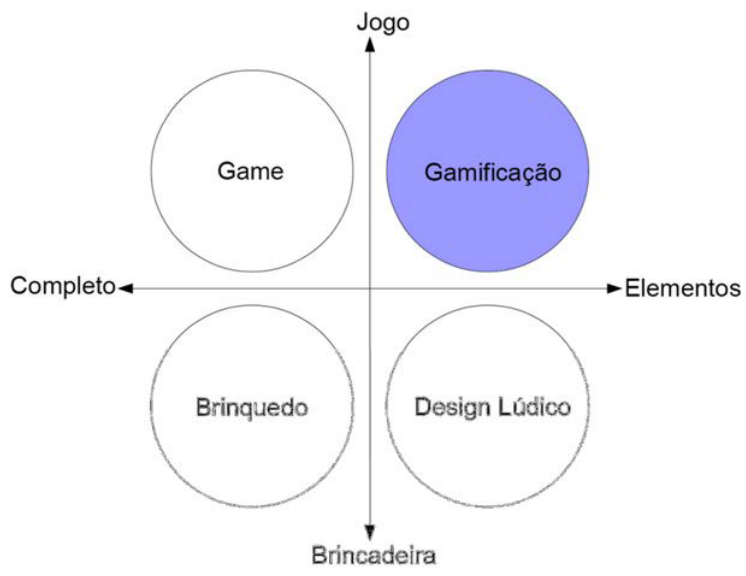

Figura 1. Contextualização da Gamificação

Fonte:[Alves 2015]

Essa concepção de game, da qual a gamificação deriva, implica em concebê-lo como um sistema, composto por elementos interconectados que, ao agregarem-se em um todo, resulta em um fenômeno que é maior do que a soma de suas partes. Dessa forma, pode-se utilizar desde um número reduzido de elementos, até uma quantia maior, fazendo com que o produto final possa produzir uma experiência próxima a de um game completo [Fardo 2013].

Quanto à escolha dos elementos, e de como aplicá-los em um contexto específico, isso depende da finalidade do projeto em questão. Pode-se construir sistemas gamificados baseados apenas em pontos, medalhas e tabelas de líderes (PBL - Points, Badges and Leaderboards), que são as mecânicas mais básicas de um game, com a finalidade única de promover mudanças no comportamento dos indivíduos através de recompensas extrínsecas, semelhantes às ideias da economia comportamental [Ladley 2011], ou pode-se construir uma experiência significativa que vá muito além do que as mecânicas básicas dos games oferecem e motivar intrinsecamente os indivíduos a desempenharem os seus papéis da melhor forma possível dentro do contexto em que se encontram [Werbach and Hunter 2012].

Segundo Fardo (2013), a gamificação se apresenta como um fenômeno emergente 
com muitas potencialidades de aplicação em diversos campos da atividade humana, pois a linguagem e metodologia dos games são bastante populares, eficazes na resolução de problemas (pelo menos nos mundos virtuais) e aceitas naturalmente pelas atuais gerações que cresceram interagindo com esse tipo de entretenimento. Ou seja, a gamificação se justifica a partir de uma perspectiva sociocultural.

\section{O Amibiente Gamificado ProGame}

O ambiente gamificado ProGame possui 4 atores principais: Administrador do sistema, Escola, Professor e Aluno. Cada ator possui funcionalidades específicas no ambiente, podendo algumas delas ser aplicadas à outro ator. O Ator Administrador do sistema, possui as funcionalidades de adicionar, remover, atualizar, pesquisar e listar as escolas. Para cada escola serão atribuídas credenciais de acesso ao ambiente ProGame (logins e senhas), que permitem a escola entrar no ambiente.

O ator Escola pode acessar as seguintes funcionalidades: adicionar, remover, atualizar, pesquisar e listar cursos, disciplinas, turmas e professores. Os cursos dizem respeito aos oferecidos pelas escolas profissionalizantes e abrangem diversas áreas como Ambiente e Saúde, Controle e Processos Industriais, Gestão e Negócios, dentre outros. A escola pode adicionar qualquer disciplina, mas o foco principal do ambiente é abordar, inicialmente, a matemática, que é uma das disciplinas avaliadas no SPAECE.

Adicionadas os cursos e as disciplinas, a escola adicionará as turmas do $1^{\circ}, 2^{\circ}$ e $3^{\circ}$ ano no ambiente, sendo cada turma associada a um curso e ano de início da mesma. Por fim, a escola adiciona os professores, preenchendo com os principais dados como nome, disciplina que ministra, a turma que leciona, e-mail principal de acesso, login de acesso ao sistema e a senha de acesso. Outras funcionalidades da escola são visualizar a quantidade de acessos dos alunos ao ambiente, listar alunos cadastrados, perguntas adicionadas e desafios gerados pelos professores.

Já os professores com suas credenciais podem: adicionar, remover, atualizar, pesquisar e listar alunos, perguntas, desafios e conquistas. Ao adicionar as perguntas, o professor deve preencher as informações a seguir: selecionar a disciplina, informar o enunciado da pergunta, adicionar imagem de apoio (se necessário), adicionar os itens da pergunta e indicar qual dos itens é o correto. Ao final o professor pode atribuir pontos a cada questão adicionada, permitindo informar o valor dos pontos em um intervalo de 1 à 100, sendo que a pontuação menor representa uma questão fácil, enquanto a maior pontuação representa uma questão muito difícil. Com as perguntas adicionadas, o professor poderá criar novos desafios para ser respondido por seus alunos.

Para adicionar um novo desafio o professor deve informar o nome do desafio, considerado como título do desafio, selecionar a qual turma será direcionado o desafio, selecionar a disciplina do desafio (caso o professor ministre mais de uma), descrever de forma sucinta os objetivos do desafio gerado pelo professor. Para se concluir o cadastro do desafio será necessário adicionar no mínimo 5 perguntas e preencher as informações supracitadas. Fica a critério do professor adicionar insignias (conquistas) por desafio, que é um dos mecanismos da gamificação implementados no ambiente e pode motivar os alunos para chegar até o fim do desafio.

Os alunos com as suas credenciais possuem acesso: Ranking,editar seu perfil, visualizar desafios disponíveis, participar de fóruns, visualizar quadro de conquistas, vi- 
VII Congresso Brasileiro de Informática na Educação (CBIE 2018)

Anais dos Workshops do VII Congresso Brasileiro de Informática na Educação (WCBIE 2018)

sualizar seu desempenho geral e acompanhar seu nível de desempenho na plataforma. A tela inicial do aluno exibe o ranking do aluno em relação aos pontos obtidos nos desafios, essa pontuação indica a posição do mesmo em comparação com os alunos da escola, turma ou curso. A funcionalidade visualizar desafios é listar todos os desafios da turma, caso o aluno deseje responder um dos desafios, basta apenas clicar no desafio desejado. Um relógio contabiliza o tempo que o aluno leva para responder o desafio. Quando o aluno finaliza o desafio, ele visualiza seu desempenho no desafio seja no formato de gráfico pu textual, indicando percentual de acerto e erro, pontos obtidos, tempo e data de conclusão do desafio.

Outros elementos de gamificação existentes no ProGame são: feedback de quais questões o aluno acertou e errou, e insignias, caso o professor tenha adicionado alguma conquista ao desafio. Se o aluno necessitar se preparar para responder os desafios, o mesmo pode utilizar a opção do fórum para montar um espaço de discussão entre os alunos e trocar ideias entre os participantes. O nível de desempenho do aluno é composto pelo total de pontos obtidos nos desafios e é representado como uma escala de 1 a 100, sendo considerado o nível 1 como iniciante na plataforma, ou seja, um aluno que respondeu poucos desafios, podendo chegar ao nível 100, que é considerado como um aluno que já respondeu muitos desafios.

A Figura 2 representa a interface gráfica dos desafios do aluno. Nessa tela são aplicados três elementos da gamificação: o primeiro é o LeadBoard que é representado pelo ranking dos 20 primeiros alunos que obtiveram mais pontos nos desafios respondidos. Esse ranking agrega o segundo elemento da gamificação, a competitividade, que estimula os alunos a obter mais pontos nos desafios. Por fim, o terceiro elemento é a mudança de nível, que indica a experiência do aluno no ambiente ProGame.

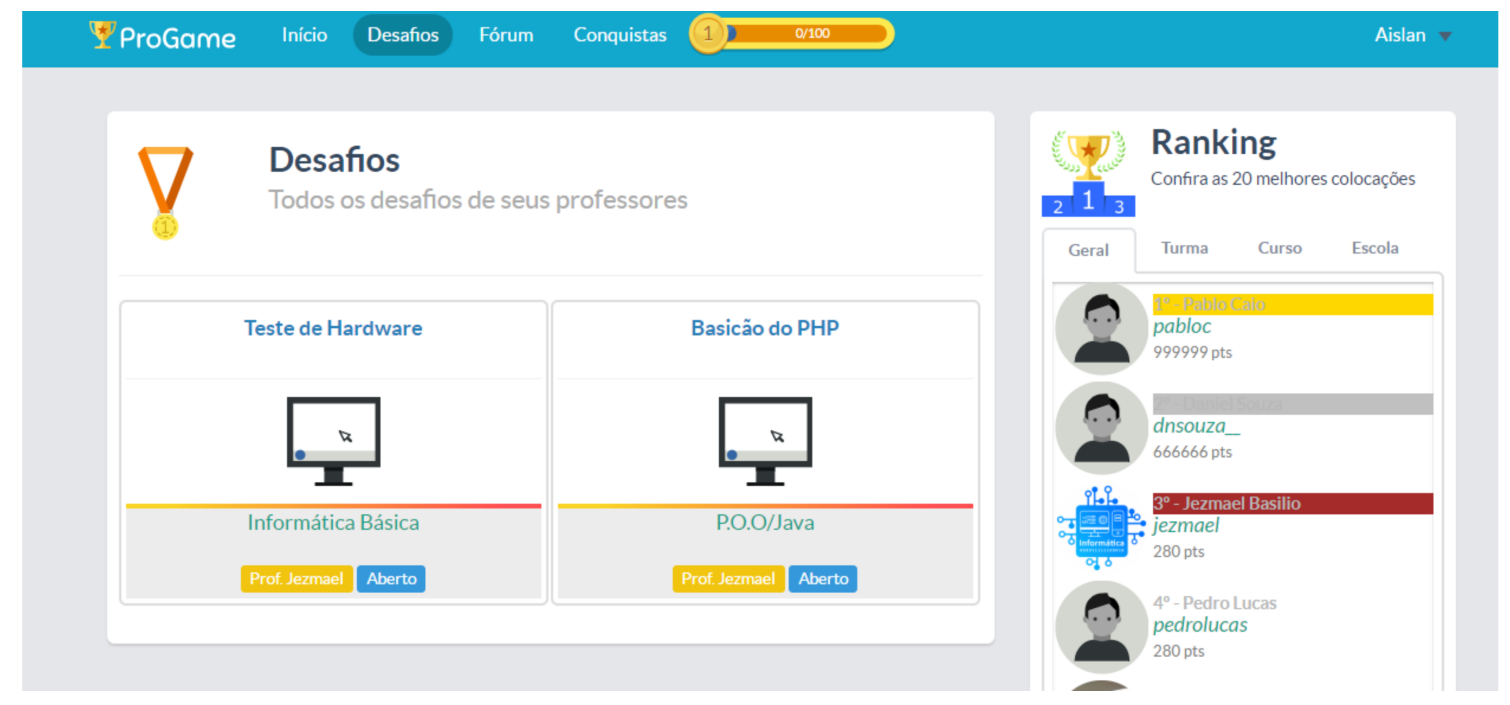

Figura 2. Tela dos desafios dos alunos

A Figura 3 mostra um exemplo do ambiente de respostas dos desafios, contendo as questões selecionadas pelos professores, exibindo o nome do desafio que está sendo respondido, o tempo decorrente do desafio, quantas questões restam para concluir, o enunciado da questão e os itens de cada questão. 
VII Congresso Brasileiro de Informática na Educação (CBIE 2018)

Anais dos Workshops do VII Congresso Brasileiro de Informática na Educação (WCBIE 2018)

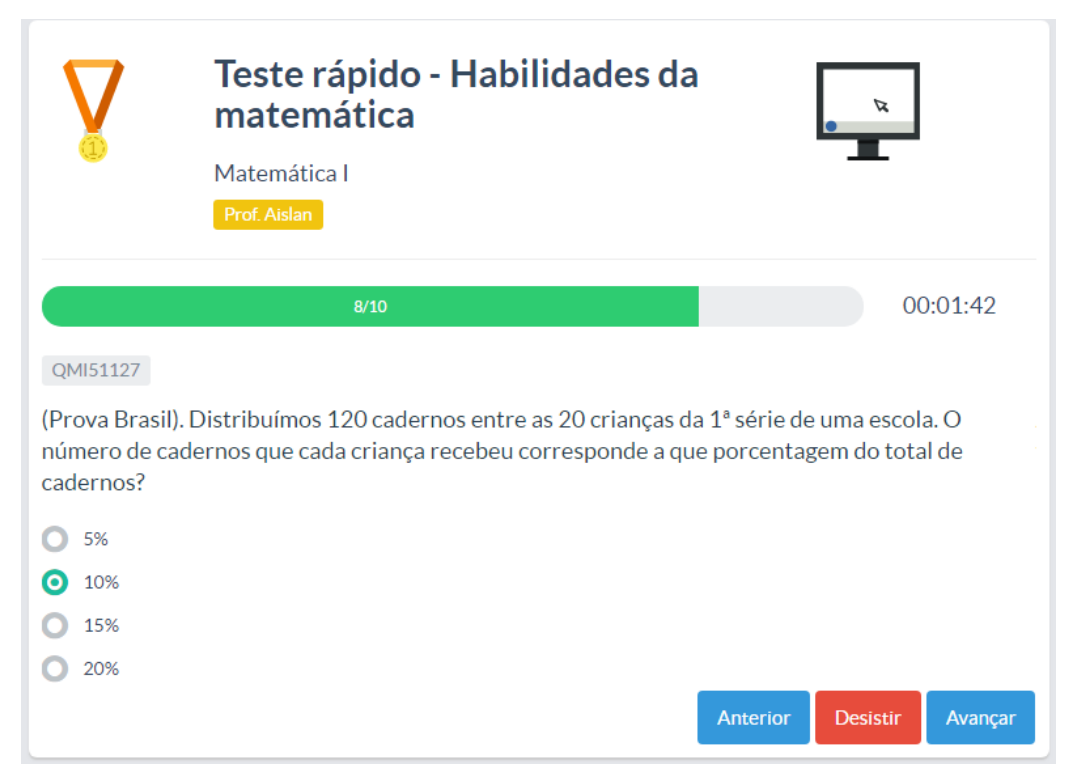

Figura 3. Exemplo da janela de respostas dos desafios

Ao final de cada desafio respondido é gerado um gráfico apresentando o desempenho do aluno, quantas questões o aluno acertou e quantas o mesmo errou no desafio, conforme ilustrado na Figura 4. Nessa janela são aplicados dois elementos da gamificação: O feedback instantâneo indicando as questões corretas e as erradas, e a divulgação do mérito, por meio da qual o aluno ganha a insignia adicionada pelo professor no desafio.

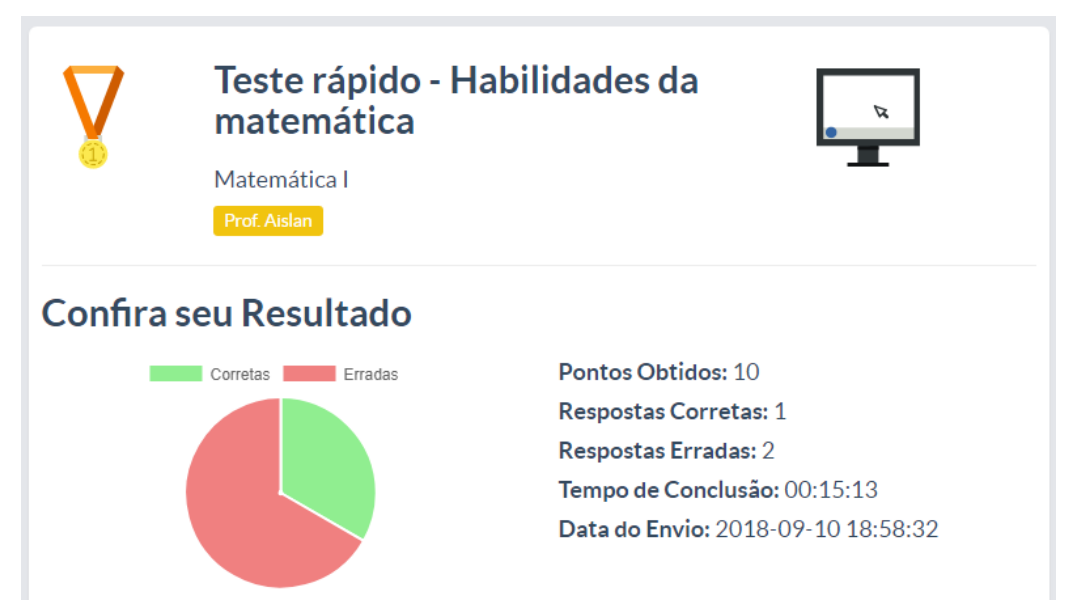

Figura 4. Janela do desempenho do aluno no desafio respondido

Outro elemento da gamificação é a colaboração interativa, que é aplicada ao fórum criado pelo aluno. O quadro de conquistas possui o elemento histórico de objetivos, no qual são expostas todas as conquistas dos alunos. Um elemento que pode ser aplicado fora do ambiente gamificado ProGame são as premiações, por meio das quais o professor pode levar em consideração os resultados obtidos como política de bonificação, como por exemplo pontos adicionados à média dos alunos ou como atividade complementar. Cada professor pode definir o tipo de premiação mais adequada aos seus alunos. 
VII Congresso Brasileiro de Informática na Educação (CBIE 2018)

Anais dos Workshops do VII Congresso Brasileiro de Informática na Educação (WCBIE 2018)

\section{Avaliação da usabilidade}

Após a construção do ambiente gamificado, 34 alunos de uma turma do $1^{\circ}$ ano do ensino médio da Escola Estadual de Educação Profissional Dr. José Iran Costa receberam credenciais (logins e senhas) para acesso ao ambiente e participaram do processo de resolução dos desafios proposto pelos professores. Em seguida, eles responderam a um questionário contendo 10 questões sobre usabilidade seguindo os padrões sugerido por [Padilha et al. 2004].

A Figura 5(a) exibe um gráfico sobre os resultados coletados dentre os 34 alunos da turma que realizaram o teste. Do total de alunos, $29(85.3 \%)$ concordaram que gostariam de utilizar a ferramenta com frequência, retratando que o ambiente gamificado possui elementos que fazem com que os alunos sintam-se mais a vontade com os recursos dispostos. A Figura 5(b) apresenta o resultado da pergunta sobre complexidade do sistema. $76.5 \%$ dos alunos afirmaram que o ProGame não é complexo. A terceira pergunta representada na Figura 5(c) indagava sobre facilidade do sistema. 28 alunos (82.3\%) concordaram que a plataforma gamificada é de fácil uso.

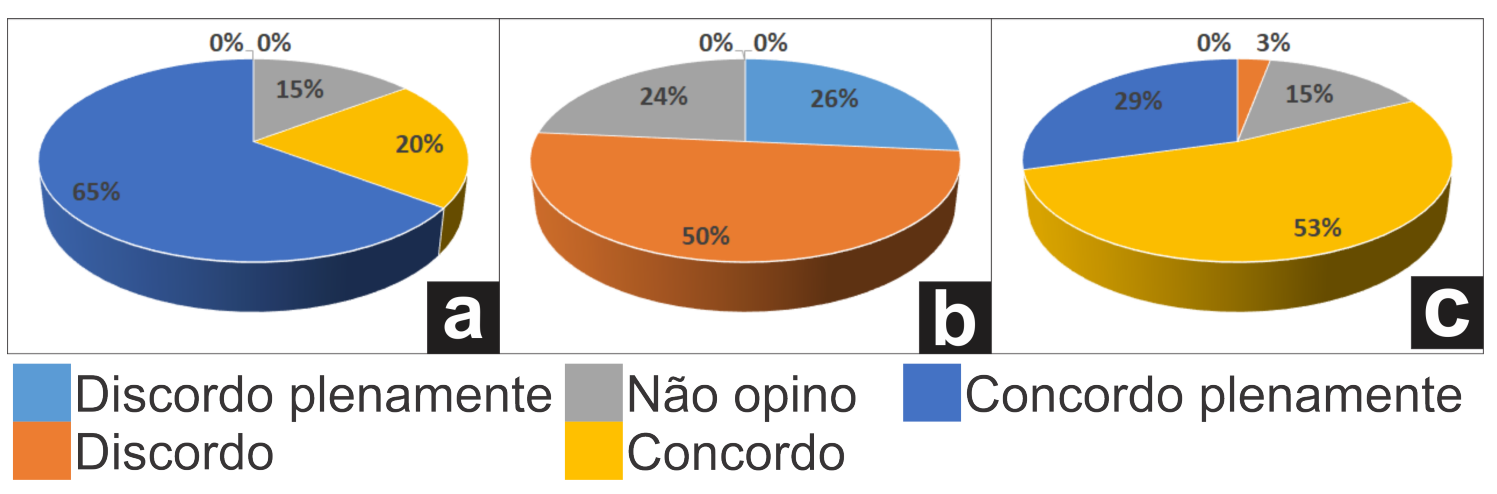

Figura 5. (a) Eu acho que gostaria de usar esse sistema com frequência. (b) Eu acho o sistema desnecessariamente complexo. (c) Eu achei o sistema fácil de usar.

Já em relação à quarta pergunta, cujas respostas são mostradas no gráfico da Figura 6(a), apenas 7 alunos (29.5\%) consideraram a importância de possuir conhecimentos mais específicos para utilizar o ambiente gamificado. O quinto questionamento discorria sobre integração entre as funções do sistema. A grande maioria dos alunos (88.2\%) concordaram que as ferramentas propostas no ProGame apresentam uma boa integração, tornando-os os satisfeitos em utilizar o ambiente. Dados conforme Figura 6(b). Os resultados obtidos sobre a pergunta de número 6, ilustrados na Figura 6(c), alertam para possíveis problemas no sistema, pois $55.9 \%$ dos alunos concordaram que o ambiente apresenta inconsistências. O sistema será reanalisado para verificar esse resultado. 
VII Congresso Brasileiro de Informática na Educação (CBIE 2018)

Anais dos Workshops do VII Congresso Brasileiro de Informática na Educação (WCBIE 2018)

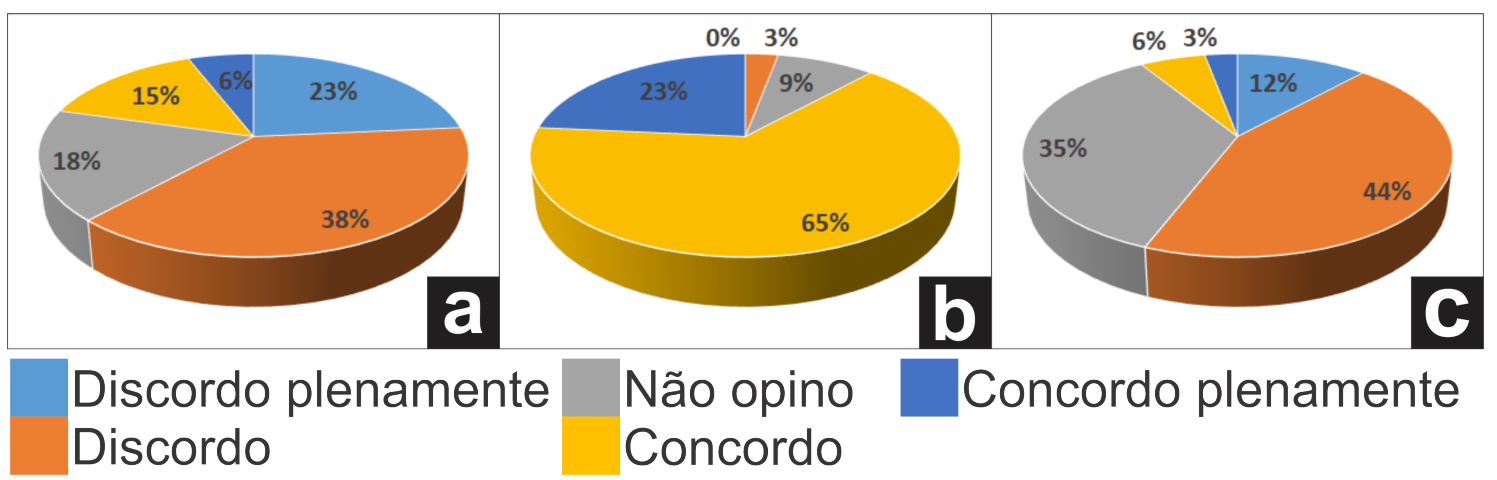

Figura 6. (a) Eu acho que precisaria de ajuda de uma pessoa com conhecimentos técnicos para usar o sistema. (b) Eu acho que as várias funções do sistema estão muito bem integradas. (c) Eu acho que o sistema apresenta muita inconsistência.

Conforme apresentado na Figura 7(a), 29 alunos (85.3\%) declaram que futuros usuários poderão aprender rapidamente o funcionamento da plataforma gamificada. A Figura 7(b) corrobora os resultados da pergunta 5(c), na qual $82 \%$ dos alunos afirmaram que o sistema não é difícil de usar. A proposta ofertada pelo ambiente gamificado apresenta um elevado grau de satisfação entre os alunos participantes da pesquisa (74\%), conforme mostrado na Figura 7(c), o que ressalta a confiabilidade depositada pelos alunos ao utilizar o ambiente gamificado. Por fim, a Figura 7(d) apresenta possui uma relação com o enuciado da Figura 6(a), as duas apresentam a necessidade de aprender algo a mais para utilizar o ProGame. Do total de respondentes, 57\% dos afirmaram que não precisaram aprender coisas novas antes de usar o sistema.

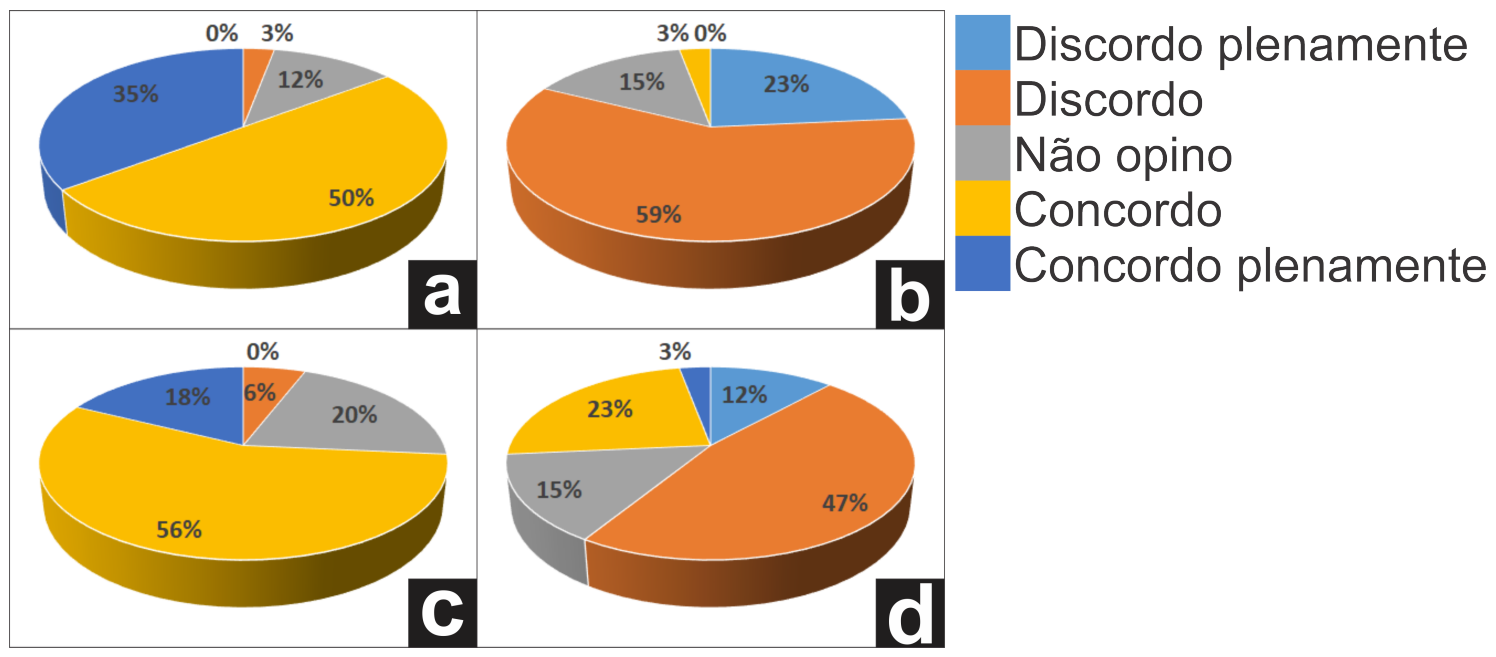

Figura 7. (a) Eu imagino que as pessoas aprenderão como usar esse sistema rapidamente. (b) Eu achei o sistema difícil de usar. (c) Eu me senti confiante ao usar o sistema. (d) Eu precisei aprender várias coisas novas antes de conseguir usar o sistema.

\section{Conclusão}

Utilizar das técnicas disponíves ou de elementos da gamificação para promover uma alternativa no processo de ensino aprendizagem dos alunos do ensino médio, pode ter efeitos 
VII Congresso Brasileiro de Informática na Educação (CBIE 2018)

Anais dos Workshops do VII Congresso Brasileiro de Informática na Educação (WCBIE 2018)

significativos, tendo em vista que a maioria dos jovens gostam de desafios ou de algo que possa submeter competitividade. Ser competitivo de forma saudável é por algo que poderá lhe render bons frutos, é satisfatório, pois é nesse sentindo que são desenvolvidos novos métodos, ou aplicações dos mesmo conhecimentos tradicionais, integrando essa nova geração dos nativos digitais.

Este trabalho apresentou um ambiente gamificado, chamado ProGame, para auxiliar no processo de aprendizagem dos alunos da $1^{\mathrm{a}}$ série do ensino médio com foco nos descritores de matemática do SPAECE. O ambiente gamificado foi testado com 34 alunos da escola EEEP Dr. José Iran, que responderam a um questionário de usabilidade. Pelos resultados, nota-se que a maioria dos alunos pretende usar o ambiente gamificado com frequência e afirma que o sistema é de fácil uso, sem necessidades de conhecimentos adicionais.

\section{Referências}

Alves, F. (2015). Gamification: Como criar experiências de aprendizagem engajadoras. DVS Editora.

Cysneiros, P. G. (2008). Papert, seymour. a máquina das crianças: repensando a escola na era da informática. Revista entreideias: educação, cultura e sociedade, 12(12).

Fardo, M. L. (2013). A gamificação aplicada em ambientes de aprendizagem. RENOTE, 11(1).

Fardo, M. L. (2014). A gamificação como estratégia pedagógica: estudo de elementos dos games aplicados em processos de ensino e aprendizagem.

Kapp, K. M. (2012). The gamification of learning and instruction: game-based methods and strategies for training and education. John Wiley \& Sons.

Ladley, P. (2011). Gamification, education and behavioural economics. Games-ED Innovation in Learning.

Luma da Rocha Seixas, Alex Sandro Gomes, I. J. M. F. R. L. R. (2014). Gamificação como estratégia no engajamento de estudantes do ensino fundamental. In $X X V$ Simpósio Brasileiro de Informática na Educação (SBIE 2014), pages 559-568.

McGonigal, J. (2011). Reality is broken: Why games make us better and how they can change the world. Penguin.

Moratori, P. B. (2003). Por que utilizar jogos educativos no processo de ensino aprendizagem. UFRJ. Rio de Janeiro.

Neto, A., da Silva, A. P., and Bittencourt, I. I. (2015). Uma análise do impacto da utilização de técnicas de gamificação como estratégia didática no aprendizado dos alunos. In Brazilian Symposium on Computers in Education (Simpósio Brasileiro de Informática na Educação-SBIE), volume 26, pages 667-678.

Padilha, A. V. et al. (2004). Usabilidade na web: uma proposta de questionário para avaliação do grau de satisfação de usuários do comércio eletrônico.

Simone de S. Borges, Helena M. Reis, V. H. S. D. I. I. B. P. A. J. e. S. I. (2013). Gamificação aplicada à educação: Um mapeamento sistemático. In XXIV Simpósio Brasileiro de Informática na Educação (SBIE 2013), pages 234-243. 
VII Congresso Brasileiro de Informática na Educação (CBIE 2018)

Anais dos Workshops do VII Congresso Brasileiro de Informática na Educação (WCBIE 2018)

Werbach, K. and Hunter, D. (2012). For the win: How game thinking can revolutionize your business. Wharton Digital Press.

Zichermann, G. and Cunningham, C. (2011). Gamification by design: Implementing game mechanics in web and mobile apps. "O'Reilly Media, Inc.". 